\title{
Establish clinical practice network platform for medical students
}

\author{
Jinguo Wang ${ }^{1,}$, the corresponding author: Na Wang ${ }^{2, b}$ \\ and Yang $\mathrm{Gao}^{3, \mathrm{c}}$ \\ ${ }^{1}$ Department of Urology, the First Hospital of Jilin University, China \\ ${ }^{2}$ Department of Anesthesiology, the First Hospital of Jilin University, China \\ ${ }^{3}$ Department of Anesthesiology, the First Hospital of Jilin University, China \\ wangjinguolily@163.com, ㅎangna080613@163.com, 975707998@qq.com ${ }^{c}$
}

\section{Keywords: medical students practical network platform}

Abstract. Medical students through a variety of forms of pre-service training, can eliminate the strangeness of the internship, fear, have confidence in upcoming internship. Realize the transition, strengthen the practice of the students' ability to adapt and their sense of mission and sense of responsibility. Strengthen the consciousness of students' learning initiative and legal security. Let the student internship with the fastest speed into the state, to master the ability of clinical skills as soon as possible, improve the effect of internship.

\section{Introduction}

Medical students through a variety of forms of pre-service training, can eliminate the strangeness of the internship, fear, have confidence in upcoming internship. Realize the transition, strengthen the practice of the students' ability to adapt and their sense of mission and sense of responsibility. Strengthen the consciousness of students' learning initiative and legal security. Let the student internship with the fastest speed into the state, to master the ability of clinical skills as soon as possible, improve the effect of internship.

Clinical practice training medical students as the basis of clinical practice and began to link, to improve the quality of medical practice is essential. Medical students in school learning theoretical knowledge and clinical practice there is a certain difference, the clinical practice provides a platform for the practice of medical students' learning. And interns to work for the first time that the character of progressive span large, weak strain capacity, poor ability to adapt, lack of language communication ability, practical ability weak, self safety consciousness, etc., in a relatively short period of time to transition the transition of the role is bound to have a bridge to connect, and internship before the pre-service training is the essence of the connotation of the embodiment. Pre-service training, therefore, to improve the quality of clinical practice plays an important role, is the basis of medical practice, is continuity in medical practice teaching link. Along with society's progress and the development of the network and the progress of the medical education, medical students pre-service training also exposed some shortcomings. Such as, training methods and contents of traditional single. Mainly adopts lecturing, on-the-spot investigation, discussion, and other forms of training, without using the Internet and other modern communication means, lack of interaction; training content focuses on the several listed above, less material, not comprehensive, lack of dynamic, diversity, systemic, slow information feedback, etc. Training time is short, not system. Students face many knowledge and skills can't well digest absorb in a few days, can't optimize the training. Again, training the lack of normative, need further internship pre-service training should be brought into the teaching the basic link, the formulation of syllabus and lecture notes, teaching plan, improve the training effect.

Medical students' pre-service training network platform for the development of the network advantages can be fully used, integrated use of various resources, use the multimedia teaching 
methods, such as network, supplemented by field teaching view, timely provide all contents pre-service training and resources conveniently, at any time make it illustrated pre-service training and delicate melody, lively and interesting. The development and utilization of the platform, solves the training time is short, the content of many contradictions and problems, you can always access to knowledge, makes comprehensive training system, is not easy to appear omissions. At the same time, the platform embodies the characteristics of dynamic, open, timely dynamic reaction between teachers and students, between, colleges and universities information, timely feedback and training effect evaluation, and deal with all sorts of problems encountered, this paper is mainly to solve the problem is based on the network design and development of medical students' practical skills training platform, the main goal is to set up to adapt to the school doctor students training and practice the characteristics of the network platform. Research process, based on modern teaching theory as a guide, pay attention to the combination of theory with practice, constantly updating the teaching idea, the application of network resources and network information technology, efforts to build proactive network training platform. This paper first expounds the research background and significance; Then reviewed the research status quo of medical students' practical skills training; And then introduces the now commonly used Web database technology, database access technology and the network platform development chooses technology; On this basis, study the function of the network platform, the structure and operating environment; Finally explained the basic platform of the network platform and each function module.

Domestic study of pre-service training is more of a qualitative discussion on the theoretical training, improve the characteristics of methods. At present, in terms of abroad, the development of education technology also earlier faster, network information technology application in the medical teaching and achieved significant effect, but because do not have enough data as the research basis.

The rapid development of modern information technology to the development of medical students' practical skills training provides the necessary conditions, so based on the characteristics of the network, to build strong pertinence, high practicality, high scalability of network training platform is the best means of medical students' practical skills training. According to medical students currently on the construction of network teaching and the importance of medical students' practical skills training, training teaching information resources as the research object, discussed under the network environment, training the basic process of design and development of information resources, to promote the medical students' practical skills training network teaching has a practical significance for the construction of information resources, at the same time improve the quality of the training of practical skills and the connotation, create a new pattern teaching practical skills training network. To gain significant teaching effect, science and advanced education ideas and teaching design process is indispensable. Education concept and to the whole teaching design, and implementation plays a guiding role, what kind of education idea will produce what kind of teaching behavior, so this design under the guidance of the scientific principles of network platform, not only in line with the advanced education concept, and to follow the law of objective and scientific teaching. The meaning of scientific principles including two aspects: On the one hand, pre-service training data upload accords with the basic law of disciplines, namely according to the inherent law of medicine, according to the requirements of training decomposition point and distinguished, by the difficult easy with focus gradually show at the same time. On the other hand, the design of teaching process in accordance with the teaching rule, so the network platform to specific teaching process is divided into classroom goals, chapter, weekly goals, as well as the ultimate goal, so to facilitate students compared to check their learning time, ensure the successful completion of the final training objectives.

With the support of information technology, the focus of the students' learning is not only learn knowledge, but to master the methods of learning and ability cultivation, such as training students' 
information literacy. Medical students use information technology to solve the problem of process is a science and rigorous, hands-on activities in a planned way, it helps to cultivate medical students' innovative spirit, understanding ability and practice ability, and through continuous training, medicine can also place this kind of problem solving skills gradually migrated to other field of study and work. In view of this, this article design fully embody the principle of autonomy, in pre-service training lesson plans, learning objectives and related information, just learning goals, not rules form and the learning time, place, medical students can according to your own knowledge background and learning habit to arrange the fast rhythm of one's own learning process, both to guarantee within the prescribed time to complete the training work, and to give opportunity and foundation of the medical students' autonomous learning [1].

Because each medical students of different levels of knowledge and learning methods, so the design of the network platform not only should meet the requirements of the advanced teaching concept, to consider different medical students of the specific situation. Only respect the difference of medical students and meet the learning needs of different medical students, can we truly achieve network platform for the medical students, for medical students practice and lifelong development foundation goals [2]. In the process of building the network platform is both integrity and pay attention to individuality principle, concrete manifestation in: For medical students to achieve the same goal of a variety of different ways, such as providing by subject content, teacher's name in a variety of ways, such as browse search mechanism; When medical teachers in providing information, also pay attention to integration of the different forms of data to achieve the same teaching goal, the individualized teaching strategy to exert students' initiative and learning are of great help/very helpful to vary from person to person, and for the same kind of teaching skill, each medical students can according to their own interest, learning habits and learning to theory knowledge reading, real teaching situation representation, case teaching and so on a variety of different ways to learn to complete, thus promotes the development of medical students' personality and potential. In general, learning can be divided into individual learning, competitive learning and cooperative learning three types. In the cooperative learning, students study effect is positively related to each other, that is when a student achieve his learning goals, the other students can achieve learning goals.

Goal is a compass of learning, only clear learning objectives, students will only be targeted for study. But if you want to set a goal, you need to be familiar with their environment. Before practice, through the network platform to provide training hospital for medical students and the basic rules and regulations, the relevant departments to help medical students in a familiar environment on the basis of clearly recognize the internship goals, and thus for the targeted learning, ready to enough, at the beginning of practice really, can quickly into clinical practice, in a short time into the work role, completes the labor of duty. At the same time due to the application of network technology, teachers' monitoring ability is abate, so to make the network platform website effectively, it is particularly important to clear learning goals. According to the teaching goal in this platform system is divided into general objective, curriculum goal, the goal unit goals and learning goals. Medical students at the beginning of learning, began to register will be to achieve different target expression layer and in the future to be present in the site [3].

In the process of pre-service training and practice, medical students will inevitably encounter various difficulties, if you can't get the timely help, will have a strong sense of frustration, the influence of medical students' positive initiative. Network platform for students to search and communication mechanism, make all kinds of help information within reach. After medical students meet with difficulties, consult the help information can be easily used search mechanism, open the link to download access to information resources; Also can through the communication mechanism, it is using E-mail, voice mail, bulletin boards, chat rooms, such as synchronous or asynchronous 
communication, seek help from teachers and classmates, to solve the problem quickly, and internalization of new knowledge in the original knowledge structure, to realize the self construction of knowledge.

Today's students are very keen to pursuit of modern technology, the traditional forms of force-feeding teaching way, if the contents of pre-service training points of frame to introduce them one by one, it will be to a great extent, so that they produce school-weary emotions and psychological, cannot fundamentally clinical practice training play a proper role. In pre-service training network platform such as images, sound, animation, organic combination, rich training materials will be displayed in front of medical students and provide them with a contains rich resources, diversity, and open learning and exploring space, but also for the development of the medical students critical thinking, creative thinking and innovation ability of provides the fertile soil. At the same time, the information resources in network platform of interactive and nonlinear organization way, conforms to the human way of thinking and cognitive characteristics, can fully mobilize the enthusiasm and initiative of medical students' learning, and is especially suitable for medical students "independent study, independent exploration" study. Medicine students, on the other hand, can survive under the guidance of teachers collection, acquisition, analysis, and using information resources provided by the network platform, abroad the most advanced medical knowledge, to realize the construction of knowledge, cultivate their analysis problem, problem-solving ability, and help them more in-depth practice purpose clearly, understand the practice work, enhance their self-confidence and sense of responsibility, it is advantageous to the medical students from the school to go to the hospital, from classroom to ward, from students to the transition of the internship. The common business of the hospital is already very complex, coupled with the management of training medical students makes the hospital related staff and uselessness, hard to avoid can appear unnecessary mistakes and failures, and provides the network platform related to hospital staff a convenient and effective way.

\section{Conclusions}

Hospitals can put the hospital and the related staff of each department rules and regulations and policy news reported on the network platform to study for medical school teachers and students online browsing and downloading, this not only is very effective to the hospital in the internship education responsibility, but also greatly reduces the hospital related personnel with the heavy task, to a certain extent, to avoid some mistakes and errors.

\section{References}

[1] Seago BL, Schlesinger JB, Hampton CL. Using a decade of data on medical student computer literacy for strategic planning. J Med Libr Assoc. 90. 202-209 (2002).

[2] Forman LJ, Pomerantz SC. Computer-assisted instruction: a survey on the attitudes of osteopathic medical students. J Am Osteopath Assoc.106. 571-578 (2006).

[3] Buabbas AJ, Al-Shawaf HM, Almajran AA. Health Sciences Students' Self-Assessment of Information and Communication Technology Skills and Attitude Toward e-Learning. JMIR Med Educ. 20. 2. e9 (2016). 